\title{
Placental Growth Hormone (GH), GH-Binding Protein, and Insulin-Like Growth Factor Axis in Normal, Growth- Retarded, and Diabetic Pregnancies: Correlations with Fetal Growth*
}

\author{
H. DAVID MCINTYRE, ROBERT SEREK, DENIS I. CRANE, TARA VEVERIS-LOWE, \\ ANNETTE PARRY, SANDRA JOHNSON, KIN C. LEUNG, KEN K. Y. HO, \\ MOHAMMED BOUGOUSSA, GEORGES HENNEN, AHMED IGOUT, \\ FUNG-YEE CHAN, DAVID COWLEY, ANDREW COTTERILL, AND ROSS BARNARD \\ Co-operative Research Center for Diagnostic Technologies and School of Life Sciences, Queensland \\ University of Technology (R.B., T.V.-L.), Brisbane, Queensland 4001; School of Biomolecular and \\ Biomedical Science, Griffith University (R.S., D.C.), Nathan, Queensland 4111; Garvan Institute of \\ Medical Research (K.-C.L., K.H.), Darlinghurst, New South Wales 2010; University of Liège, \\ Laboratory of Endocrinology (A.I., M.B., G.H.) and Mater Mothers' Hospital (H.D.M., F.-Y.C., D.C., \\ A.C., A.P., S.J.), South Brisbane, Queensland 4101, Australia
}

\begin{abstract}
We previously described significant changes in GH-binding protein (GHBP) in pathological human pregnancy. There was a substantial elevation of GHBP in cases of noninsulin-dependent diabetes mellitus and a reduction in insulin-dependent diabetes mellitus. GHBP has the potential to modulate the proportion of free placental GH (PGH) and hence the impact on the maternal $\mathrm{GH} /$ insulin-like growth factor I (IGF-I) axis, fetal growth, and maternal glycemic status. The present study was undertaken to investigate the relationship among glycemia, GHBP, and PGH during pregnancy and to assess the impact of GHBP on the concentration of free PGH. We have extended the analysis of specimens to include measurements of GHBP, PGH, IGF-I, IGF-II, IGF-binding protein-1 (IGFBP-1), IGFBP-2, and IGFBP-3 and have related these to maternal characteristics, fetal growth, and glycemia. The simultaneous measurement of GHBP and PGH has for the first time allowed calculation of the free component of PGH and correlation of the free component to indexes of fetal growth and other endocrine markers. PGH, free PGH, IGF-I, and IGF-II were substantially decreased in IUGR at 28-30 weeks gestation (K28) and 36-38 weeks gestation (K36). The mean concentration ( \pm SEM) of total PGH increased significantly from K28 to K36 (30.0 \pm 2.2 to $50.7 \pm 6.2$
\end{abstract}

$\mathrm{ng} / \mathrm{mL} ; \mathrm{n}=40)$, as did the concentration of free PGH $(23.4 \pm 2.3$ to $43.7 \pm 6.0 \mathrm{ng} / \mathrm{mL} ; \mathrm{n}=38$ ). The mean percentage of free PGH was significantly less in IUGR than in normal subjects $(67 \%$ vs. $79 \% ; P<$ 0.01). Macrosomia was associated with an increase in these parameters that did not reach statistical significance. Multiple regression analysis revealed that PGH/IGF-I and IGFBP-3 account for $40 \%$ of the variance in birth weight. IGFBP-3 showed a significant correlation with IGF-I, IGF-II, and free and total PGH at K28 and K36. Noninsulin-dependent diabetes mellitus patients had a lower mean percentage of free PGH $(65 \% ; P<0.01)$, and insulin-dependent diabetics had a higher mean percentage of free PGH $(87 \% ; P<0.01)$ than normal subjects. Mean postprandial glucose at K28 correlated positively with $\mathrm{PGH}$ and free PGH (consistent with the hyperglycemic action of $\mathrm{GH}$ ). GHBP correlated negatively with both postprandial and fasting glucose. Although GHBP correlated negatively with PGH $(\mathrm{r}=-0.52 ; P<.001)$, free $\mathrm{PGH}$ and total $\mathrm{PGH}$ correlated very closely $(\mathrm{r}=0.98)$. The results are consistent with an inhibitory function for GHBP in vivo and support a critical role for placental GH and IGF-I in driving normal fetal growth. (J Clin Endocrinol Metab 85: 11431150,2000
$\mathrm{L}^{2}$ ATE PREGNANCY is a catabolic phase with redistribution of maternal nutrients to support fetal growth (1). Work by Gluckman (2) and others has shown fetal growth to be dependent on maternal substrate supply, and the hormonal mechanisms driving these changes are beginning to be elucidated. Placental GH $(\mathrm{PGH})$ progressively replaces pituitary $\mathrm{GH}$ (hGH-N) in the maternal circulation from midgestation (3).

Received August 2, 1999. Revision received October 21, 1999. Accepted December 4, 1999.

Address all correspondence and requests for reprints to: Dr. Ross Barnard, Co-operative Research Center for Diagnostic Technologies and School of Life Sciences, Queensland University of Technology, Gardens Point, Brisbane, Queensland 4001, Australia; or Dr. David McIntyre, Mater Mothers' Hospital, South Brisbane, Queensland 4101, Australia.

* This work was supported by grants from Novo-Nordisk Australia, the Mater Hospital J. P. Kelly Foundation, Serono Australia, and the Convention Region Wallone, Universite de Liege.
Placental GH is a major regulator of maternal insulin-like growth factor I (IGF-I) $(4,5)$ and has a spectrum of metabolic activities comparable to that of hGH-N (6) and a similar somatogenic effect (7). The high levels of PGH measured from midgestation in human pregnancy (8) are likely to impact on placental metabolism and substrate supply to the fetus, either directly or mediated by IGF-I $(2,5,9,10)$. This is supported by observations that maternal concentrations of total PGH and IGF-I correlate strongly and are decreased in cases of intrauterine growth retardation (IUGR) $(5,8,11)$ and that maternal IGF-I correlates with fetal femur length and birth weight (12). Furthermore, the administration of hGH to pregnant rats impacts on fetal weight $(13,14)$. It has been demonstrated that GH does not cross the placenta in pregnant rats (15), so it is likely that its effects on fetal growth are indirect and mediated by effects on maternal IGF-I concentrations and on substrate supply to the fetus. 
The effects of PGH on maternal metabolism, on the placenta, and hence on fetal growth are potentially modulated by the high affinity $\mathrm{GH}$-binding protein (GHBP) (16-18). In the maternal circulation GHBP concentrations are comparable or higher than the levels in the nonpregnant state, depending on gestational stage $(19,20)$. However, to date there have been no studies relating the concentration of free PGH to maternal biochemical parameters or to fetal growth. For better understanding of the $\mathrm{GH}$ axis during pregnancy it is necessary to have measurements of the gestational profile of free PGH in normal and pathological pregnancies. A comparison of the correlations between free PGH and growth parameters and between total PGH and growth parameters would also provide evidence relevant to the impact of maternal GHBP on fetal growth and, more generally, on the physiological role of GHBP in the control of GH action in vivo.

We have previously described significant changes in GHbinding protein (GHBP) in human pregnancy (19). That study demonstrated a reduction in GHBP with advancing gestation and a positive correlation between GHBP and maternal weight and body mass index (BMI). Another finding of that study was the substantial elevation of GHBP across all stages of gestation in cases of noninsulin-dependent diabetes mellitus (NIDDM), which contrasted with the reduction in GHBP in insulin-dependent diabetes mellitus (IDDM). The existence of divergent GHBP concentrations in these different forms of diabetes prompted the present study to investigate the relationship among changes in glycemia, PGH, and changes in GHBP during pregnancy.

Therefore in the present work we have extended the analysis of specimens from our previous study (19) to include measurements of PGH, free PGH, IGF-I, IGF-II, IGF-binding protein-1 (IGFBP-1), IGFBP-2, and IGFBP-3, and we have related these to maternal characteristics, fetal growth, and glycemia. Finally, the present study was undertaken to determine whether any combination of these biochemical variables could predict birth weight.

\section{Subjects and Methods}

Consent forms and study protocols were approved by the Mater Mothers' Hospital and Queensland University of Technology ethics committees. Subjects gave formal written consent to participate in the study after receiving appropriate written and verbal information.

Patient characteristics have previously been described in detail (19). The current study used all available samples taken in the third trimester from patients with prepregnancy IDDM $(n=13), \operatorname{NIDDM}(n=6)$, and IUGR $(n=16)$ pregnancies. A subset of samples from normal pregnancies $(n=23)$ was analyzed for comparative purposes. Normal women underwent a 50-g nonfasting glucose challenge test at 28 weeks gestation to exclude gestational diabetes.

In the light of previous data regarding PGH secretion $(4,5,8)$, samples taken at 28-30 weeks gestation (K28) or at 36-38 weeks gestation (K36) were analyzed. Ultrasonographic fetal assessments were performed at K28 and K36 to assess fetal growth.

Fetal outcome data collected at delivery included weeks of gestation, gender, birth weight, head circumference, and crown-heel length. The z (SD) scores for birth weight, corrected for gestational age and gender $[\mathrm{z}=$ birth weight - mean birth weight/sD (birth weight) ] were calculated for each baby to allow comparison of relative fetal growth across a range of gestational ages.

Categories of fetal growth were defined prospectively as follows: IUGR, birth weight less than 10th percentile; normal, birth weight more than 10th and less than 90th percentiles; and macrosomia, birth weight more than 90th percentile. Normative data were derived from a con- temporary cohort of 21,221 singleton babies born at the Mater Mothers' Hospital.

\section{Glycemic control records}

In a subset of the patients with IDDM $(n=9)$ or NIDDM $(n=6)$, records of glycemic control were available from home monitoring and from clinic visits, all using the ACCUTREND reflectance glucose monitor (Roche Molecular Biochemicals, Mannheim, Germany). For each patient, the mean of self-monitored capillary glucose measurements taken while fasting and $2 \mathrm{~h}$ after breakfast was calculated in addition to a mean value for capillary glucose measurements taken at clinic visits. Mean capillary glucose values for each patient (fasting, postprandial, and at the clinic) were calculated using all available measurements between 20 and 30 weeks gestation. These mean values therefore represent overall glycemia around the time of the K28 blood sampling and have been used in the correlation analyses described below to explore the relationship between glycemia and parameters of GH metabolism.

\section{Laboratory methods}

All GHBP measurements were performed using the ligand immunofunctional assay for GHBP as reported previously $(19,21)$. PGH was assayed using the recombinant PGH standards and monoclonal antibodies E8 and 7C12 developed by Hennen's group (22-24) in an ${ }^{125} \mathrm{I}-$ labeled sandwich immunoassay assay. In our hands the mean intraassay coefficient of variation was $7.7 \%$, and the interassay coefficient of variation was $9.3 \%$. Free PGH was calculated according to the algorithm and computer program of Barsano and Baumann (25), as applied previously by Cramer et al. (26), using the paired values of GHBP and PGH measured in each serum sample and using the affinity for native human GHBP measured by Barnard et al. (18).

Serum IGF-I and IGF-II were assayed using modifications of published RIA protocols after extraction of serum with acetone and formic acid $(27,28) .{ }^{125}$ I-Labeled IGF-I and IGF-II tracers were purchased from Amersham Pharmacia Biotech (Aylesbury, UK). Primary incubation with rabbit anti-IGF-I or IGF-II antiserum (GroPep Pty. Ltd., Adelaide, Australia) for $16 \mathrm{~h}$ was followed by immunoprecipitation with Sac-cel anti-rabbit antibody and counting. For the IGF-I, interassay CVs at the lower and upper ends of the sensitive range were $14.5 \%$ and $17.7 \%$, respectively. For IGF-II, interassay CVs at the lower and upper ranges were $16.4 \%$ and $11.7 \%$, respectively.

IGFBP-1, -2, and -3 were assayed using immunoradiometric assay kits supplied by Diagnostics Systems Laboratories, Inc. (Webster, TX). Reported intraassay CVs of these assays were 2.7-5.2\% for IGFBP-1, 4.7$8.5 \%$ for IGFBP-2, and $1.8-3.9 \%$ for IGFBP-3. Interassay CVs for these assays were $3.5-6.0 \%, 4.5-7.4 \%$, and $0.5-1.9 \%$ for IGFBP-1 to -3 , respectively.

\section{Statistical analysis}

Differences between serum hormone concentrations at K28 and K36 and between groups of patients classified by growth (normal, IUGR, and macrosomic) and diagnosis (normal, IDDM, NIDDM, and IUGR) were analyzed using ANOVA and covariance. Significant differences were further examined using the least significant difference test. Linear correlation analysis was used to explore the relationships between continuous variables, and the $r$ values quoted are Pearson's correlation coefficients.

Forward stepwise multiple regression analysis was used to develop a biochemical model for the prediction of birth weight using all GHrelated variables and to examine the influence of glycemia on PGH and GHBP concentrations. In all cases, $\mathrm{F}>1.0$ was required for variables to enter the model. For all analyses, statistical significance was accepted at the $5 \%$ level on two-tailed testing. All statistical analyses were performed using Statistica for Windows (StatSoft, Tulsa, OK).

\section{Results}

Data from a total of 58 women with singleton pregnancies were included in this study. Maternal and fetal characteristics are summarized in Table 1 . Women with NIDDM 
TABLE 1. Maternal and fetal characteristics

\begin{tabular}{|c|c|c|c|c|c|c|c|c|}
\hline $\begin{array}{l}\text { Diagnostic } \\
\text { group }\end{array}$ & $\mathrm{n}$ & $\underset{(y r)}{\text { Maternal age }}$ & $\begin{array}{l}\text { Maternal } \\
\text { wt(kg) }\end{array}$ & $\begin{array}{l}\text { Maternal BMI } \\
\left(\mathrm{kg} / \mathrm{m}^{2}\right)\end{array}$ & $\begin{array}{l}\text { Birth wt } \\
\text { (z-score) }\end{array}$ & $\begin{array}{l}\text { Birth } \\
\text { wt (g) }\end{array}$ & $\begin{array}{l}\text { Head circumference } \\
(\mathrm{cm})\end{array}$ & $\begin{array}{l}\text { Crown-heel } \\
\text { length }(\mathrm{cm})\end{array}$ \\
\hline IDDM & 13 & 26.5 & $70.6(4.0)^{a}$ & $26.4(1.2)$ & $0.76(0.25)^{b}$ & $3346(126)$ & $34.3(0.4)$ & $51.4(0.6)$ \\
\hline NIDDM & 6 & $27.7(1.6)$ & $95.0(9.8)^{b}$ & $36.2(2.7)^{c}$ & $0.53(0.26)$ & 3356 (131) & $34.1(0.4)$ & $48.8(1.5)$ \\
\hline
\end{tabular}

Characteristics of mothers recruited into the study and of their babies at birth, classified by diagnostic group. Birth weight SD (z-scores) are corrected for gestational age at delivery and for gender. Figures in parentheses are SEMs.

${ }^{a} P<0.05$ vs. normals.

${ }^{b} P<0.01$ vs. normals.

${ }^{c} P<0.01$ vs. all other groups.

FIG. 1. Total and free PGH by growth category (IUGR, <10th percentile; Macro, $>90$ th percentile) at K28 and K36. a, $P<0.01 ; \mathrm{b}, P<0.05$ (vs. IUGR).
Total and free PGH by Growth and Gestation

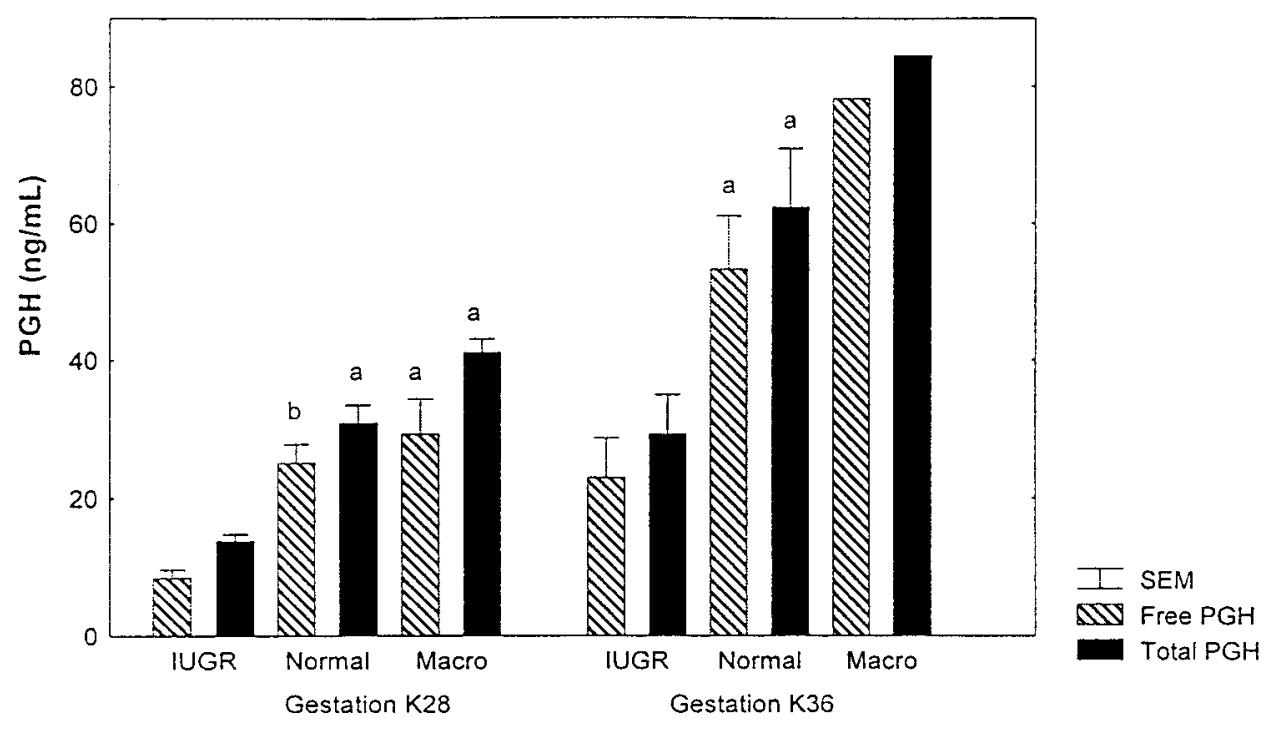

showed significantly greater body mass and BMI. Because of this and because our previous study (19) showed a positive correlation between BMI and GHBP levels, an analysis of covariance was performed using maternal weight and BMI as covariates when examining the outcome parameters. The results were congruent with those obtained without analysis of covariance. In the interests of simplicity the uncorrected means are reported in the tables and figures. As expected, birth weight $\mathrm{z}$-scores were higher than normal in IDDM pregnancies $(P<0.01)$ and lower in IUGR $(P<0.001)$. The IUGR group also demonstrated significantly reduced head circumference and crown-heel length.

\section{Effects of gestation}

Mean maternal total PGH concentrations increased by $69 \%$ from K28 to K36 $(P<0.01)$. GHBP levels did not change significantly over this period, as noted in our previous study (19), but free PGH rose by $87 \%(P<0.01)$. No significant differences were noted in levels of IGF-I, IGF-II, IGFBP-1, IGFBP-2, or IGFBP-3 at these two gestational ages.

\section{Effects of diagnosis}

At both $\mathrm{K} 28$ and K36, women recruited because of antenatally detected IUGR showed lower levels of PGH and free PGH than normal subjects [free PGH, $24.25 \pm 2.62 \mathrm{ng} / \mathrm{mL}$ (normal) vs. $8.46 \pm 1.16 \mathrm{ng} / \mathrm{mL}$ (IUGR) at K28 $(P<0.01)$; $54.87 \pm 8.31 \mathrm{ng} / \mathrm{mL}$ (normal) vs. $22.96 \pm 5.67 \mathrm{ng} / \mathrm{mL}$ (IUGR) at K36 $(P<0.01)$; Fig. 1]. In addition, IUGR patients showed higher levels of GHBP at K28 and K36 (Figs. 2 and 3). Levels of IGF-I and IGF-II were reduced in IUGR (Figs. 4 and 5) Analysis of the IGFBPs showed no consistent pattern, although IGFBP-3 levels were somewhat lower in IUGR patients at $\mathrm{K} 36(P<0.05)$.

The diabetic subjects showed some additional changes in GH-related parameters. Total PGH levels were similar to those in normal subjects, but reduction of GHBP in IDDM and elevation of GHBP in NIDDM compared to normal subjects (both $P=0.02$ ) were noted at K28. As a consequence of changes in the GHBP concentration, at K28 the percentage of free PGH was lower in NIDDM subjects than in normal subjects $(62 \%$ vs. $74 \% ; P<0.05)$ and higher in IDDM than in normal subjects $(84 \%$ vs. $74 \%$; $P<0.05)$. At $\mathrm{K} 36$ this trend was also significant, with a reduced percentage of free PGH in NIDDM (69\% vs. $85 \% ; P<0.05)$ and an increased percentage in IDDM relative to that in normal subjects (91\% cf. $85 \%$; $P<$ 0.05). IGFBP-2 levels were higher in IDDM and NIDDM subjects than in normal subjects at K28 $(P<0.05)$. Both NIDDM and IDDM patients demonstrated higher levels of PGH, free PGH, IGF-I, and IGF-II at K28 than the IUGR patients. 
FIG. 2. PGH, GHBP, and free PGH at K28, classified by diagnostic group. a, $P<0.01$ vs. normal subjects; $\mathrm{b}, P<0.05$ vs. normal subjects; c, $P<0.01$ vs. IUGR; d, $P<0.01$ vs. NIDDM; e, $P<$ 0.05 vs. NIDDM

FIG. 3. PGH, GHBP, and free PGH at K36, classified by diagnostic group. a, $P<0.01 ; \mathrm{b}, P<0.05$ (vs. normal subjects).
PGH and GHBP at K28

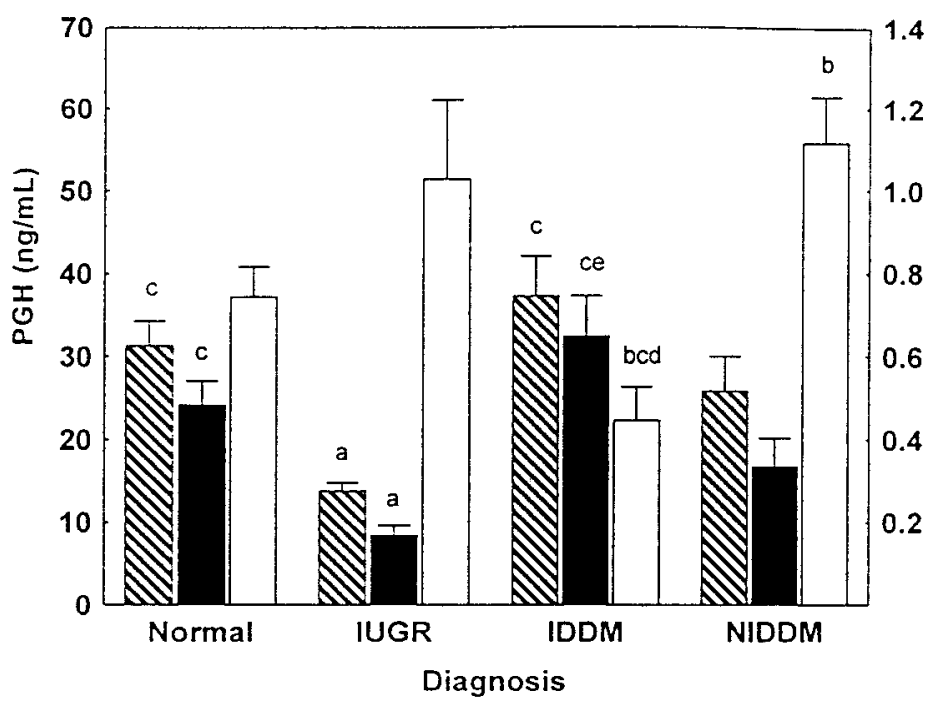

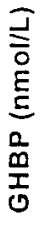

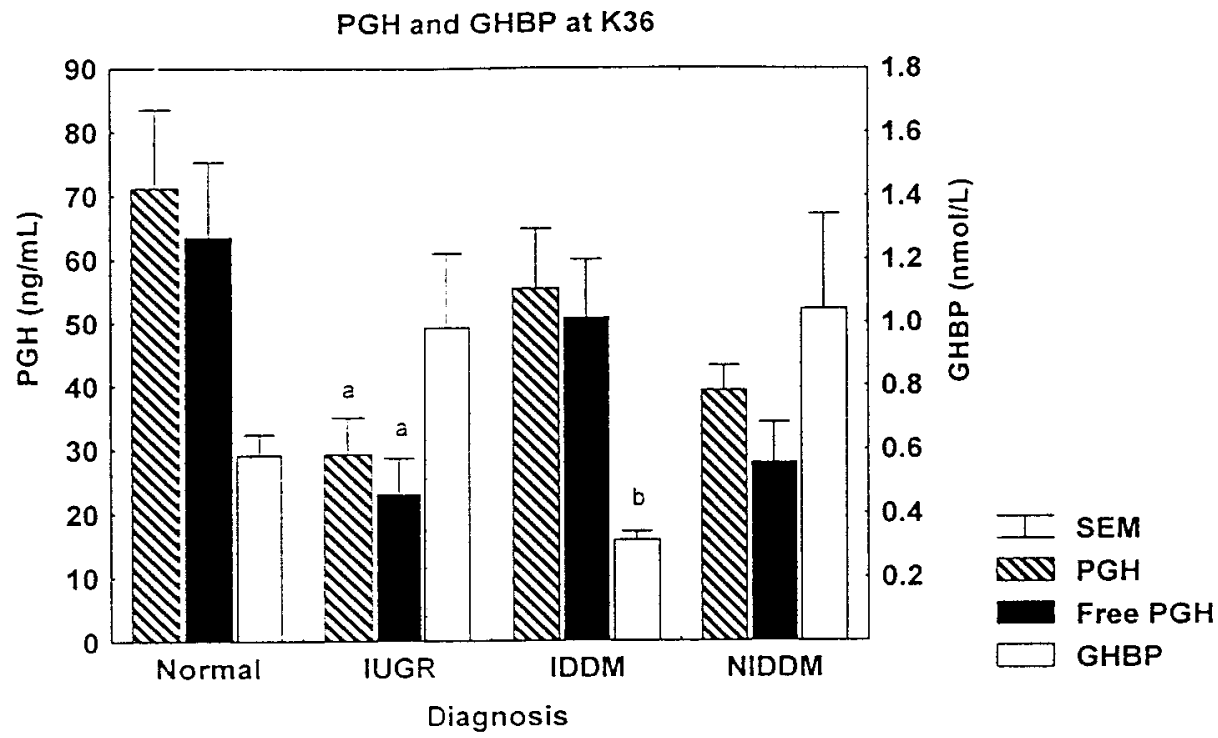

\section{Effects of fetal size}

The results were also analyzed using the predefined growth categories (IUGR, $<10$ th percentile, $\mathrm{n}=16$; normal, $\mathrm{n}=36$; macrosomia, $>90$ th percentile, $\mathrm{n}=6$ ), as outlined above. In this analysis, recruitment diagnosis was not considered.

The results found were congruent with those outlined above for the recruitment diagnosis, with reductions in $\mathrm{PGH}$, free PGH, IGF-I, and IGF-II found in IUGR at both gestational ages $(P<0.01)$. Macrosomia was associated with slightly higher numerical values for most of these parameters, but the differences were not statistically significant. IGFBP-1 at K28 showed a significant negative correlation with birth weight $(\mathrm{r}=-0.35)$, but no correlation at K36.

\section{Free vs. total GH}

The calculated percentage of total placental GH present in the unbound state varied significantly with diagnosis (by
ANOVA, $P<0.0001)$, but not with gestation. In normal subjects $79 \pm 2 \%(\mathrm{n}=33)$ of total PGH was unbound compared to $67 \pm 4 \%$ in IUGR ( $n=19 ; P<0.01), 65 \pm 4 \%$ in $\operatorname{NIDDM}(\mathrm{n}=9 ; \mathrm{P}<0.01)$, and $87 \pm 2 \%$ in IDDM $(\mathrm{n}=17 ; \mathrm{P}=$ $0.06)$.

\section{Correlation analysis}

One of the primary aims of the study was to determine the value of estimations of maternal GH-related parameters as predictors of fetal growth. In the correlation analysis (see Tables 2 and 3), levels of hormonal parameters at K28 and K36 were correlated with birth weight $\mathrm{z}$-scores, and the interrelationship of the various GH-related parameters was also explored.

Total PGH, free PGH, and IGF-II correlated positively with z-score at both K28 and K36. IGFBP-1 showed a negative correlation with Z-score only at K28, whereas IGF-I correlated positively with birth weight at K36. As shown in Table 
Fig. 4. Free PGH, IGF-I, and IGF-II and sum of IGF-I plus IGF-II by diagnostic category at K28. a, $P<0.01$; b, $P<0.05$ (vs. normal subjects)
Fig. 5, Free PGH, IGF-I, and IGF-II and sum of IGF-I plus IGF-II by diagnostic category at K36. a, $P<0.01$ vs. normal subjects
Free $\mathrm{PGH}$ and IGF at $\mathrm{K} 28$
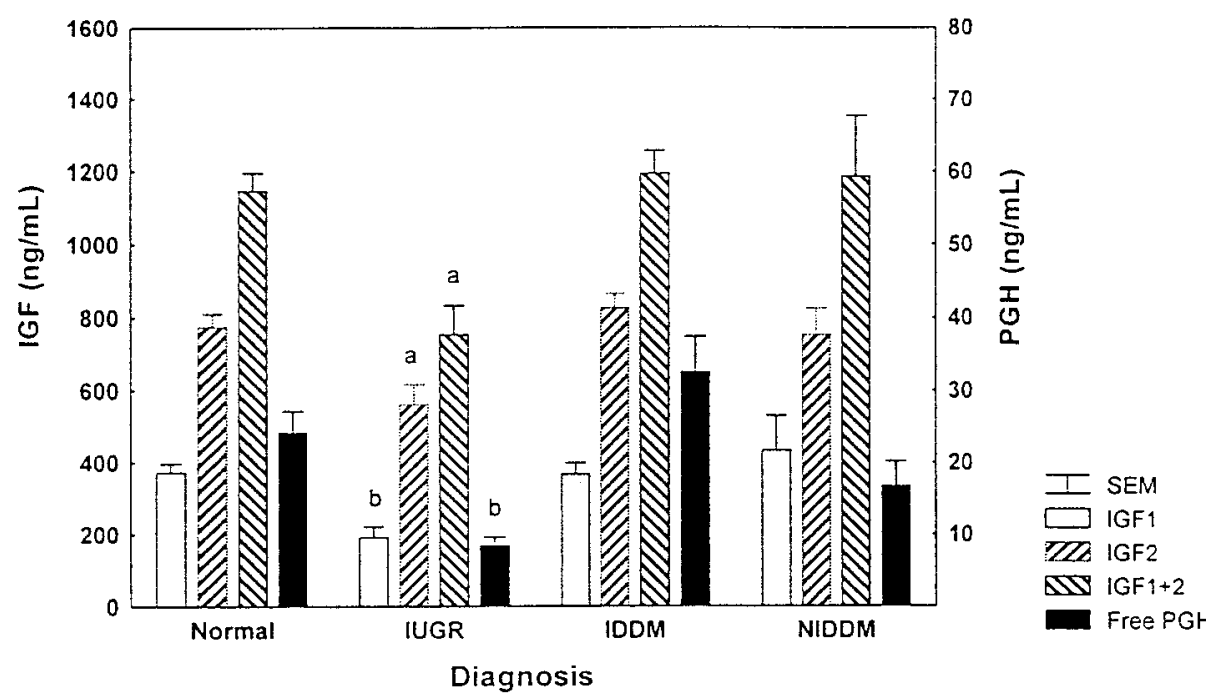

Free PGH and IGF at K36

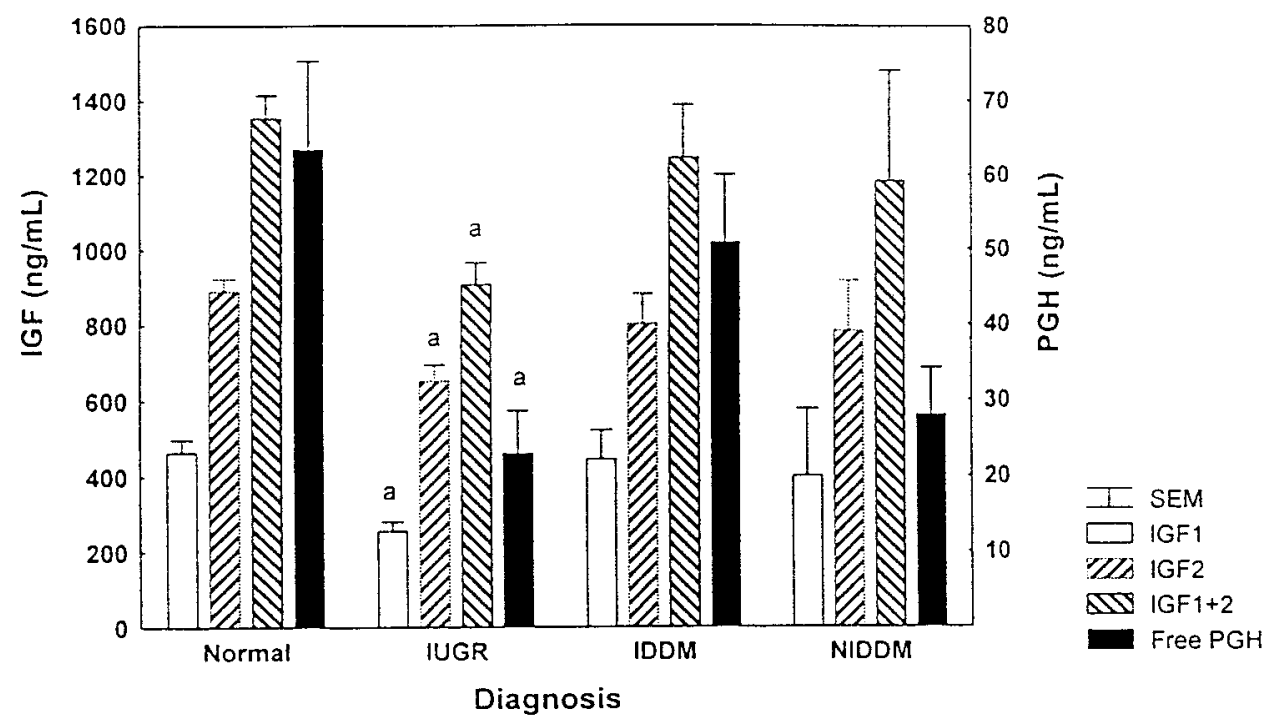

2, PGH, free PGH, and IGF-I measured at K36 correlated positively, whereas GHBP correlated negatively with head circumference and crown-heel length, suggesting an overall positive effect of PGH on fetal size. Interestingly, only PGH and free PGH correlated significantly with ponderal index (birth weight/crown-heel length ${ }^{3}$ ) which is a measure of relative fetal adiposity.

Forward stepwise multiple regression analysis was used to determine whether any combination of GH-related variables was able to predict birth weight z-score. At K28, an $\mathrm{r}$ of $0.64\left(\mathrm{r}^{2}=0.41 ; P<0.01\right)$ was obtained, with IGF-II, IGFBP-1, PGH, GHBP, and IGFBP-3 retained in the model as significant variables. At $\mathrm{K} 36$ an $\mathrm{r}$ of $0.59\left(\mathrm{r}^{2}=0.35 ; P<0.01\right)$ was noted, with IGF-I, free PGH, and IGFBP-3 retained in the model. These results suggest that these GH-related variables may account for up to $40 \%$ of the observed variance in birth weight.

PGH and free PGH correlated closely $(r=0.98-0.99)$. PGH correlated negatively with GHBP at both gestational ages. At
K28, PGH correlated positively with IGF-II, but not with IGF-I. At K36, significant positive correlations with both IGF-I and IGF-II were seen.

IGFBP-3 showed a significant positive correlation with IGF-I and IGF-II at both gestational ages. IGFBP-3 also correlated significantly with free and total PGH at K28 and K36.

\section{Effects of glycemia}

Linear correlation analysis of the effects of maternal glycemia on GH parameters showed significant effects related to postprandial glucose levels (Table 4). At K28, there was a positive correlation between mean postprandial glucose and PGH $(\mathrm{r}=0.57 ; P=0.03)$, free PGH $(\mathrm{r}=0.64 ; P=0.01)$, and IGFBP-3 ( $\mathrm{r}=0.57 ; P=0.03)$. GHBP correlated negatively with both postprandial glucose $(\mathrm{r}=-0.56 ; P=0.03)$ and fasting glucose $(\mathrm{r}=-0.58 ; P=0.03)$ at K28. Insufficient glucose data were available at K36 for an adequate correla- 
TABLE 2. GH parameters and growth parameters at birth

\begin{tabular}{lccccc}
\hline Variable & Gestation & $\begin{array}{c}\text { Birth wt } \\
\text { z-score }\end{array}$ & $\begin{array}{c}\text { Head } \\
\text { circumference }\end{array}$ & $\begin{array}{c}\text { Crown-heel } \\
\text { length }\end{array}$ & $\begin{array}{c}\text { Ponderal } \\
\text { index }\end{array}$ \\
\hline PGH & 28 & $0.39^{a}$ & & & \\
PGH & 36 & $0.42^{b}$ & $0.33^{a}$ & $0.35^{a}$ & $0.35^{a}$ \\
GHBP & 28 & -0.25 & & & \\
GHBP & 36 & -0.25 & $-0.58^{b}$ & $-0.60^{b}$ & \\
Free PGH & 28 & $0.37^{a}$ & & & \\
Free PGH & 36 & $0.43^{b}$ & $0.34^{a}$ & $0.43^{b}$ & $0.38^{a}$ \\
IGF-I & 28 & 0.27 & & & \\
IGF-I & 36 & $0.51^{b}$ & $0.36^{a}$ & $0.51^{b}$ & \\
IGF-II & 28 & $0.45^{b}$ & & & \\
IGF-II & 36 & $0.37^{a}$ & & $0.37^{a}$ & \\
IGFBP-1 & 28 & $-0.35^{a}$ & & & \\
IGFBP-1 & 36 & 0.04 & & & \\
IGFBP-2 & 28 & -0.003 & & & \\
IGFBP-2 & 36 & -0.06 & & & \\
IGFBP-3 & 28 & 0.21 & & & \\
IGFBP-3 & 36 & 0.18 & & & \\
\hline
\end{tabular}

Pearson correlation coefficients between GH-related parameters measured in maternal serum at 28 and 36 weeks gestation and indexes of fetal growth at birth. All correlations are quoted for birth weight SD (z) score. For head circumference, crown-heel length, and ponderal index (weight/crown-heel length ${ }^{3}$ ), only statistically significant correlations are shown.

${ }^{a} P<0.05$.

${ }^{b} P<0.01$

TABLE 3. Correlations: PGH and free PGH vs. other GH-related variables

\begin{tabular}{lcc}
\hline Variable & PGH & Free PGH \\
\hline a) Gestation K 28 & $-0.52^{a}$ & $-0.66^{a}$ \\
GHBP & 0.19 & 0.12 \\
IGF-I & $0.55^{a}$ & $0.55^{a}$ \\
IGF-II & 0.13 & 0.17 \\
IGFBP-1 & 0.30 & $0.43^{a}$ \\
IGFBP-2 & $0.43^{a}$ & $0.43^{a}$ \\
IGFBP-3 & & \\
b) Gestation K 36 & $-0.32^{b}$ & $-0.37^{b}$ \\
GHBP & $0.52^{a}$ & $0.52^{a}$ \\
IGF-I & $0.32^{b}$ & $0.33^{b}$ \\
IGF-II & -.004 & 0.008 \\
IGFBP-1 & 0.08 & 0.12 \\
IGFBP-2 & $0.45^{a}$ & $0.47^{a}$ \\
IGFBP-3 & & \\
\hline
\end{tabular}

$\mathrm{r}$ values are shown.

${ }^{a} P<0.01$.

${ }^{b} P<0.05$

tion analysis. Our previous study (19) showed a positive correlation between GHBP levels, and maternal prepregnancy weight and BMI. Because of the possibility that this effect may have been influencing our conclusions about the relationship between glycemia and PGH and GHBP levels, multiple regression analysis combining both measures of maternal size (weight, height, and BMI) and of maternal glycemia (fasting, postprandial, and clinic-measured glucose) as determinants of PGH and GHBP was also undertaken at K28. Data for all of these variables were available for 13 women.

Forward stepwise multiple regression with $\mathrm{PGH}$ as the dependent variable showed $r=0.80, r^{2}=0.65$, and $P=0.05$, with postprandial glucose, maternal BMI, fasting glucose, and maternal weight retained in the model. With GHBP as the dependent variable, the analysis showed $r=0.89, r^{2}=$
TABLE 4. Glycemia and GH parameters at gestation K 28

\begin{tabular}{lrcc}
\hline Variable & $\begin{array}{c}\text { Mean clinic } \\
\text { glucose }\end{array}$ & $\begin{array}{c}\text { Mean fasting } \\
\text { glucose }\end{array}$ & $\begin{array}{c}\text { Mean postprandial } \\
\text { glucose }\end{array}$ \\
\hline PGH & 0.49 & 0.24 & $0.57^{a}$ \\
GHBP & -0.39 & $-0.58^{a}$ & $-0.56^{a}$ \\
Free PGH & 0.48 & 0.38 & $0.64^{b}$ \\
IGF-I & -0.06 & -0.23 & -0.01 \\
IGF-II & 0.44 & 0.21 & 0.45 \\
IGFBP-1 & 0.02 & 0.14 & 0.27 \\
IGFBP-2 & 0.33 & 0.44 & 0.39 \\
IGFBP-3 & 0.24 & 0.27 & $0.57^{a}$ \\
\hline
\end{tabular}

Pearson correlation coefficients between mean maternal glycemia (at clinic visits, fasting and $2 \mathrm{~h}$ postprandial) and GH-related parameters in patients with diabetes.

${ }^{a} P<0.05$.

${ }^{b} P<0.01$.

0.79 , and $P<0.001$, with maternal weight and postprandial glucose retained. Using free PGH as the dependant variable, we obtained $\mathrm{r}=0.83, \mathrm{r}^{2}=0.69$, and $P<0.02$, with postprandial glucose, BMI, and fasting glucose retained in the model.

These multiple regression results suggest that glycemia is related to PGH concentrations by mechanisms independent of maternal weight and BMI. Further, maternal weight and BMI influence both PGH and GHBP levels.

IGFBP-1 did not show significant correlation with indexes of glycemia at K28 or K36, but was significantly lower in NIDDM than in normal subjects at K28 $(P<0.02)$.

\section{Discussion}

There have been a number of reports supporting a critical role for maternal IGFs and maternal GH as determinants of fetal growth $(11-14,22)$. The present report is the first in which PGH, GHBP, IGFs, and IGFBPs in late pregnancy have all been measured in the same sample set. This has allowed calculation of the free component of placental GH and correlation of the free component with indexes of fetal growth and other endocrine markers.

Our previous study (19) of the same cohort and another study (29) suggested that there may be a link between the glycemic status of patients and the concentration of GHBP and, hence, the concentration of free GH. In the current work we have also attempted to address this hypothesis.

A highly significant correlation was found between PGH and birth weight and between free PGH with birth weight at both K28 and K36. This is consistent with the finding of Evain-Brion et al. for total PGH $(11,22)$. Correlations and significance levels were very similar for free and total PGH, reflecting the tight correlation between free and total PGH $(r=0.98-0.99)$. Note that IGF-I and IGF-II also correlated well with birth weight, consistent with previous studies. IGF-I and IGF-II correlated strongly with each other at both gestation stages, consistent with observations by Ferguson et al. (12). Interestingly, although PGH and free PGH concentrations doubled between K28 and K36, IGF concentrations did not change significantly, suggesting a decrease in IGF responsiveness to $\mathrm{GH}$ between these gestational ages. The elevation in GH along with its continuous, rather than pulsatile, secretion are congruent with the well known clinical 
observation of increased glycemia and insulin resistance during later pregnancy.

IUGR patients showed higher levels of GHBP at K28 and $\mathrm{K} 36$ along with reduced PGH concentration. Fisker et al. (30) reported that GH replacement in GH-deficient adults resulted in a reduction in GHBP that was secondary to decreased adiposity. Another recent GH replacement study in GH-deficient adults (31) found a very strong three-way correlation $(r>0.81)$ among adiposity, serum leptin, and GHBP. Indeed, our earlier study (19) of normal and diabetic pregnancies found a significant correlation between BMI and GHBP. However, the elevated concentration of GHBP in IUGR pregnancy does not appear to result from increased adiposity, because the mean maternal BMI of the IUGR group was not significantly different from that in the normal group.

The present study was also undertaken to determine whether any combination of biochemical variables could predict birth weight. At K28 the combination of IGF-II, IGFBP-1, PGH, GHBP, and IGFBP-3 was the strongest predictor of birth weight. At K36 a combination IGF-I, free PGH, and IGFBP-3 was the best predictor. These results show that maternal GH-related parameters account for up to $40 \%$ of the observed variance in birth weight.

IGFBP-1 at K28 showed a significant negative correlation with birth weight $(\mathrm{r}=-0.35)$, but not at K36. This is consistent with the observations of Baldwin et al. (32). They reported a correlation coefficient at K20-K24 $(\mathrm{r}=-0.368)$ very similar to the one we measured at K28 $(r=0.35)$ and a weaker but significant negative correlation at K30-K34. In the nonpregnant state IGFBP-1 is thought to regulate the availability of IGF-I. In pregnancy its observed relationship to fetal size suggests a similar role that is independent of PGH status, as IGFBP-I showed no correlation with PGH, but showed a significant negative correlation with birth weight.

At both gestational ages IGFBP-3 correlated significantly with free and total PGH. IGFBP-3 is an index of functionality of the GH/IGF axis in the nonpregnant state (33) with the IGFBP-3 gene under direct control of a GH-responsive promoter (34). Our results suggest that this GH-responsive promoter is likely to have an active regulatory role during pregnancy.

There were significant correlations of PGH and free PGH with IGF-II at both gestational ages, but although the correlation coefficients for IGF-I were similar at K28 and K36, it was significant only at K36. Our finding is consistent with a number of studies $(5,8,22)$ that showed decreased maternal serum IGF-I in IUGR, but differs from the results of Witznitzer et al. (35). The latter group did not find a correlation between maternal serum IGF-I and birth weight after week 37, but their study did not include cases of IUGR.

IGFBP-1 did not show a significant correlation with indexes of glycemia at K28 or K36. By contrast, Baldwin et al. (32) found a negative correlation in the third trimester between IGFBP-1 and glucose levels after a 50-g oral glucose tolerance test. Our different result probably reflects methodological differences, because our measurements were taken during fasting and $2 \mathrm{~h}$ after breakfast, rather than after an oral glucose load. Although IGFBP-1 did not show significant negative correlation with indexes of glycemia, it was significantly lower in NIDDM patients than in normal subjects at K28 $(P<0.02)$. The latter result could be consistent with suppression of IGFBP-1 by elevated insulin, as observed in the nonpregnant state $(36,37)$.

PGH, free PGH, and IGFBP-3 were all strongly correlated with glycemia at K28. This is consistent with the well established antiinsulin and hyperglycemic action of $\mathrm{GH}(38,39)$. Whereas GH correlated positively with glycemia, GHBP correlated negatively. This may be consistent with GHBP normally functioning to inhibit GH metabolic actions in vivo [as it does in vitro (40-43)]. Limited published data concerning PGH regulation in vitro and in vivo suggested inhibition of PGH secretion at high glucose concentrations and stimulation of PGH during hypoglycemia. Patel et al. (44) described a concentration-dependent inhibition of PGH secretion by glucose in human placental explants and in trophoblast cultures, whereas Bjorkland et al. (45) described a mean $27 \%$ increase in PGH during a hyperinsulinemic hypoglycemic clamp (glucose, $2.2 \mathrm{mmol} / \mathrm{L}$ ) in pregnant IDDM subjects. However, this increase in PGH was detected at glucose levels well below the normal range. It appears to represent a counterregulatory response to hypoglycemia, as seen with pituitary GH in the nonpregnant state. Another group (46) described reduction in PGH concentrations during an oral glucose tolerance test in women with gestational diabetes. This also suggests an inhibitory effect of acute hyperglycemia on PGH secretion.

In light of these studies we might have expected to see a counterregulatory decrease in GH concentrations in response to hyperglycemia. However, we observed a positive correlation between PGH and glycemic status, suggesting that the physiological relationship between long term glycemia and PGH in pregnant patients with diabetes may be different. In our patients glucose was generally somewhat elevated chronically, and no patient demonstrated frank hypoglycemia. In the chronic situation we hypothesize that PGH levels are driving increased glycemia, rather than responding to glycemia in a counterregulatory mechanism.

In general, total PGH and free PGH correlate very closely. This would tend to keep the free or bioavailable GH within tightly set limits for a particular subject, particularly as secretion of $\mathrm{PGH}$, unlike that of pituitary human $\mathrm{GH}$, is not pulsatile $(5,47)$. Our observations in this and our previous study indicate that large excursions in GHBP concentration only appear to occur in chronic pathological states, such as NIDDM and IUGR, where the levels are elevated and cause a significant reduction in the free fraction of PGH.

In conclusion, maternal free PGH, total PGH, and IGF-I correlate significantly with fetal weight. Free and total PGH correlate strongly with postprandial glycemia at K28. Moreover, maternal GH-related parameters, taken together, account for up to $40 \%$ of the observed variance in birth weight. In rodents (48) maternal treatment with IGF-I has been associated with an increase in messenger ribonucleic acid for the placental glucose transporters GLUT1 and GLUT3. As GLUT1 is thought to be responsible for glucose transport from mother to placenta and GLUT3 to be responsible for glucose transport from placenta to fetus, this observation, if congruent in humans, would provide a causal link between maternal GH-related parameters and fetal size. 


\section{References}

1. Freinkel N, Metzger BE. 1992 Metabolic changes in pregnancy. In: Wilson JD, Foster DW, eds. Williams textbook of Endocrinology, 8th Ed. Philadelphia: Saunders; 993-1005.

2. Gluckman PD, Harding JE, Oliver MH, et al. 1993 Mechanisms of intrauterine growth retardation: role of fetal and maternal hormones. In: Muller EE, Cocchi $\mathrm{D}$, Locatelli V, eds. Growth hormone and somatomedins during lifespan. New York: Springer-Verlag; 147-160

3. Frankenne F, Closset J, Gomez F, Scippo ML, Smal J, Hennen G. 1988 The physiology of growth hormones (GHs) in pregnant women and partial characterization of the placental GH variant. J Clin Endocrinol Metab. 66:1171-1180.

4. Caufriez A, Frankenne F, Englert Y, Golstein J, Cantraine F, Hennen G, Copinschi G. 1990 Placental growth hormone as a potential regulator of maternal IGF-I during human pregnancy. Am J Physiol. 258:E1014-E1019.

5. Caufriez A, Frankenne F, Hennen G, Copinschi G. 1993 Regulation of maternal IGF-I by placental GH in normal and abnormal human pregnancies. Am J Physiol. 265:E572-E577.

6. Goodman HM, Tai L-R, Ray J, Cooke NE, Liebhaber SA. 1991 Human growth hormone variant produces insulin-like and lipolytic responses in rat adipose tissue. Endocrinology. 129:1779-1783.

7. Igout A, Frankenne F, L'Hermite-Baleriaux M, Martin A, Hennen G. 1995 Somatogenic and lactogenic activity of the recombinant $22 \mathrm{kDa}$ isoform of human placental gropwth hormone. Growth Regul. 5:60-65.

8. Mirlesse V, Frankenne F, Alsat E, Poncelet M, Hennen G, Evain-Brion D. 1993 Placental growth hormone levels in normal pregnancy and in pregnancy with intrauterine growth retardation. Pediatr Res. 34:439-442.

9. Chard T. 1989 Hormonal control of growth in the human fetus. J Endocrinol. 123:3-9.

10. Wang HS, Chard T. 1992 The role of insulin-like growth factor-I and insulinlike growth factor-binding protein-1 in the control of human fetal growth. J Endocrinol. 132:11-19.

11. Evain-Brion D. 1994 Hormonal regulation of fetal growth. Horm Res. 42:207-214.

12. Ferguson S, Rogers M, Chung T, Chard T, Wang HS, Owens P, Moyse K. 1994 IGF-I and IGFBP-I in pregnancy are related to glucose metabolism and fetal growth. Proc of the 3rd Int Symp on Insulin-Like Growth Factors. Growth Regul. 4(Suppl 1):112.

13. Jorgensen KD, Svendsen O, Agergaard N, Skydsgaard K. 1991 Effect of human growth hormone on the reproduction of female rats. Pharmacol Toxicol. $68: 14-20$

14. Spencer GSG, Robinson GM, Berry CJ, Dobbie PM. 1994 Alteration of maternal growth hormone levels during pregnancy influences both fetal and postnatal growth in rats. Biol Neonate. 66:112-118.

15. Fholenhag KI, Sandstrom IM, Malmlof K, Skottner AI, Nyberg FJ. 1994 Human growth hormone does not cross the placenta of the pregnant rat. Growth Regul. 4:181-187.

16. Baumann G, Stolar MW, Amburn K, Barsano CP, DeVries BC. 1986 A specific growth-hormone binding protein in human plasma: initial characterization. J Clin Endocrinol Metab. 62:134-141.

17. Herington AC, Ymer S, Stevenson J. 1986 Identification and characterization of specific binding proteins for growth hormone in normal human sera. J Clin Invest. 77:1817-1823.

18. Barnard R, Quirk P, Waters MJ. 1989 Characterization of the growth hormonebinding protein of human serum using a panel of monoclonal antibodies. J Endocrinol. 123:327-332.

19. Barnard R, Chan F-Y, McIntyre HD. 1997 Growth hormone-binding protein in normal and pathological gestation: correlations with maternal diabetes and fetal growth. J Clin Endocrinol Metab. 82:1879-1884

20. Blumenfeld Z, Barkey RJ, Youdim MBH, Brandes JM, Amit T. 1992 Growth hormone $(\mathrm{GH})$-binding protein regulation by estrogen, progesterone, and gonadotropins in human: the effect of ovulation induction with menopausal gonadotropins, GH and gestation. J Clin Endocrinology Metab. 75:1242-1249.

21. Rajkovic IA, Valiontis E, Ho KKY. 1994 Direct quantitation of growth hormone binding protein (rGHBP) in human serum by a ligand immunofunctional assay: comparison with immunoprecipitation and chromatographic methods. J Clin Endocrinol Metab. 78:772-777.

22. Evain-Brion D, Alsat E, Igout A, Frankenne F, Hennen G. 1994 Placental growth hormone variant: assay and clinical aspects. Acta Paediatr 83(Suppl 399):49-51.

23. Igout A, Frankenne F, McNamara M. Human placental growth hormone: a new monoclonal antibody for the study of its physiopathology [Abstract 1127]. Proc of the 75th Annual Meet of The Endocrine Soc.1993.

24. Igout A, Van Beeumen J, Frankenne F, Scippo ML, DeVreese B, Hennen G. 1993 Purification and biochemical characterization of recombinant human placental growth hormone produced in E. coli. Biochem J. 295:719-724.

25. Barsano CP, Baumann G. 1989 Editorial: simple algebraic and graphic methods for the apportionment of hormone (and receptor) into bound and free fractions in binding equilibria; or how to calculate bound and free hormone? Endocrinology. 124:1101-1106.

26. Cramer SD, Barnard R, Engbers C, Ogren L, Talamantes F. 1992 Expression of the growth hormone receptor and growth hormone binding protein during pregnancy in the mouse. Endocrinology. 131:876-882.

27. Holly JMP, Biddlecombe RA, Dunger DB, et al. 1988 Circadian variation of GH-dependent IGF-binding protein in diabetes and its relationship to insulin. A new role for insulin? Clin Endocrinol (Oxf). 29:667-675.

28. Blum WF, Ranke MB, Bierich JR. 1988 A specific radioimmunoassay for insulin-like growth factor-II: the interference of the insulin-like growth factor binding proteins can be blocked by excess insulin like growth factor-I. Acta Endocrinol (Copenh). 118:374-380.

29. Bjarnason R, Hagenas L, Ritzen M, Carlsson LMS. Growth hormone binding protein (GHBP) levels in children are positively correlated to peak insulin levels [Abstract P2-293]. Proc of the 10th Int Congr of Endocrinol. 1996; 478.

30. Fisker S, Vahl N, Hansen TB, Jorgensen JOL, Hagen C, Orskov H, Christiansen JS. 1998 Growth hormone (GH) substitution for one year normalizes elevated GH-binding protein levels in GH-deficient adults secondary to a reduction in body fat. A placebo controlled trial. Growth Hormone IGF Res. 8:105-112.

31. Florkowski CM, Barnard R, Livesey JH, Veveris T, Espiner EA, Donald RA. 1999 Growth hormone binding protein correlates strongly with leptin and percentage body fat in GH-deficient adults, is increased by GH replacement but does not predict IGF response. Growth Hormone IGF Res. 9:35-40.

32. Baldwin S, Chung M, Chard T, Wang HS. 1993 Insulin-like growth factorbinding-protein-1, glucose tolerance and fetal growth in human pregnancy. J Endocrinol. 136:319-325.

33. Juul A, Kastrup KW, Pedersen SA, Skakkebaek NE. 1997 Growth hormone $(\mathrm{GH})$ provocative retesting of 108 young adults with childhood-onset $\mathrm{GH}$ deficiency and the diagnostic value of insulin-like growth factor I (IGF-I) and IGF-binding protein-3. J ClinEndcorinol Metab. 82:1195-1201.

34. Albiston AL, Saffery R, Herington AC. 1995 Cloning and characterization of the promoter for the rat insulin-like growth factor-binding protein-3 gene. Endocrinology. 136: 696-704.

35. Witznitzer A, Reece EA, Homko C, Furman B, Mazor M, Levy J. 1998 Insulinlike growth factors, their binding proteins, and fetal macrosomia in offspring of nondiabetic women. Am J Perinatol. 15:23-28.

36. Underwood LE. 1996 Nutritional regulation of IGF-I and IGFBPs. J Pediatr Endocrinol Metab. 9(Suppl 3):303-312.

37. Holst N, Kierulf KH, Seppala M, Koistinen R, Jacobsen MB. 1997 Regulation of insulin-like growth factor-binding protein-1 and progesterone secretion from human granulosa-luteal cells: effects of octreotide and insulin. Fertil Steril. 68:478-482.

38. Davidson MB. 1987 Effect of growth hormone on carbohydrate and lipid metabolism. Endocr Rev. 8:115-129.

39. Moller N, Jørgensen JO, Schmitz O, et al. 1990 Effects of a growth hormone pulse on total and forearm substrate fluxes in humans. Am J Physiol. 258:E86-E91.

40. Lim L, Spencer SA, McKay P, Waters MJ. 1990 Regulation of growth hormone $(\mathrm{GH})$ bioactivity by a recombinant human GH-binding protein. Endocrinology. 127:1287-1291.

41. Mannor DA, Winer LM, Shaw MA, Baumann G. 1991 Plasma growth hor mone $(\mathrm{GH})$-binding proteins: effect on $\mathrm{GH}$ binding to receptors and $\mathrm{GH}$ action. J Clin Endocrinol Metab. 73:30-34.

42. Hansen BS, Hjorth S, Welinder BS, Skriver L, De Meyts P. 1993 The growth hormone $(\mathrm{GH})$-binding protein cloned from human IM-9 lymphocytes modulates the down-regulation of GH receptors by 22- and 20-kilodalton human $\mathrm{GH}$ in IM-9 lymphocytes and the biological effects of the hormone in $\mathrm{Nb} 2$ lymphoma cells. Endocrinology. 133:2809-2817.

43. Dattani MT, Hindmarsh PC, Brook CG, Robinson IC, Marshall NJ. 1994 Inhibition of growth hormone bioactivity by recombinant human growth hormone-binding protein in the eluted stain assay system. J Endocrinol. 140:445-453.

44. Patel N, Alsat A, Igout A, Baron F, Hennen G, Porquet D, Evain-Brion D. 1995 Glucose inhibits placental GH secretion, in vitro. J Clin Endocrinol Metab. 80:1743-46

45. Bjorklund AO, Adamson UKC, Carlstrom KAM, Hennen G, Igout A, Lins PES, Westgren LMR. 1998 Placental hormones during induced hypoglycaemia in pregnancy women with insulin-dependent diabetes mellitus: evidence of an active role for placenta in hormonal counter-regulation. Br J Obstet Gynaecol. 105:649-655.

46. Alsat E, Guibourdenche J, Couturier A, Evain-Brion D. 1998 Physiological role of placental growth hormone. Mol Cell Endocrinol. 140:121-127.

47. Nickel B, Kardami E, Cattini PA. 1990 Differential expression of human placental growth hormone variant and chorionic somatomammotropin in culture. Biochem J. 267:653-658.

48. Bauer MK, Harding JE, Bassett NS, et al. 1998 Fetal growth and placental function. Mol Cell Endocrinol. 140:115-120. 